\title{
Alignment and absolute wavelength calibration of imaging Bragg spectrometers
}

G. Bertschinger, , O. Marchuk, and, and R. Barnsley

Citation: Review of Scientific Instruments 87, 11E343 (2016); doi: 10.1063/1.4963163

View online: http://dx.doi.org/10.1063/1.4963163

View Table of Contents: http://aip.scitation.org/toc/rsi/87/11

Published by the American Institute of Physics

\section{Articles you may be interested in}

Two crystal $x$-ray spectrometers for OMEGA experiments

Review of Scientific Instruments 87, 11E335 (2016); 10.1063/1.4961284

Development of a high resolution $\mathrm{x}$-ray spectrometer for the National Ignition Facility (NIF)

Review of Scientific Instruments 87, 11E344 (2016); 10.1063/1.4962053

A neutron activation spectrometer and neutronic experimental platform for the National Ignition Facility (invited)

Review of Scientific Instruments 87, 11D702 (2016); 10.1063/1.4962871

Automated analysis of hot spot X-ray images at the National Ignition Facility

Review of Scientific Instruments 87, 11E334 (2016); 10.1063/1.4962184

Two-color spatial and temporal temperature measurements using a streaked soft x-ray imager

Review of Scientific Instruments 87, 11E313 (2016); 10.1063/1.4960160

Combined neutron and x-ray imaging at the National Ignition Facility (invited)

Review of Scientific Instruments 87, 11 D703 (2016); 10.1063/1.4962194

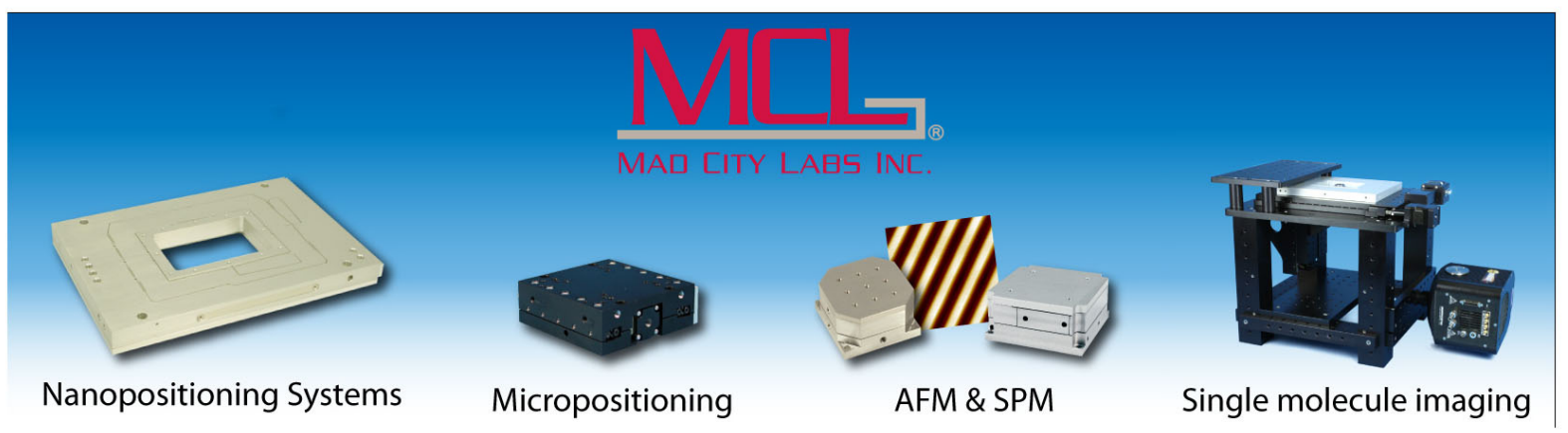




\title{
Alignment and absolute wavelength calibration of imaging Bragg spectrometers
}

\author{
G. Bertschinger, ${ }^{1, a)}$ O. Marchuk, ${ }^{2}$ and R. Barnsley ${ }^{3}$ \\ ${ }^{1}$ Bertschinger GmbH $\mathcal{E}$ Co. KG, Riedwasen 2-4, D-78554 Aldingen, Germany \\ ${ }^{2}$ Institute of Energy and Climate Research IEK-4, Plasma Physics, D 52425 Jülich, Germany \\ ${ }^{3}$ ITER Organization, F-13108 Saint-Paul-Lez-Durance, France
}

(Presented 8 June 2016; received 17 June 2016; accepted 7 September 2016; published online 26 September 2016)

In the present and the next generation of fusion devices, imaging Bragg spectrometers are key diagnostics to measure plasma parameters in the hot core, especially ion temperature and plasma rotation. The latter quantities are routinely obtained using the Doppler-width and -shift of the emitted spectral lines, respectively. Line shift measurements require absolute accuracies $\Delta \lambda / \lambda$ of about $10 \mathrm{ppm}$, where $\lambda$-is the observed wavelength. For ITER and the present fusion devices, spectral lines of He-and H-like argon, iron, and krypton as well as Ne-like tungsten are foreseen for the measurements. For these lines, $\mathrm{K} \alpha$ lines can be found, some in higher order, which fit into the narrow energy window of the spectrometers. For arbitrary wavelength settings, $\mathrm{K} \alpha$ lines are also used to measure the miscut of the spherical crystals; afterwards the spectrometers can be set according to the geometrical imaging properties using coordinate measurement machines. For the spectrometers measuring Ly $\alpha$ lines of $\mathrm{H}$-like ions, fluorescence targets can provide in situ localized calibration lines on the spectra. The fluorescence targets are used best in transmission and are excited by the thermal $\mathrm{x}$-ray radiation of the plasma. An analytic theory of fluorescence is worked out. Published by AIP Publishing. [http://dx.doi.org/10.1063/1.4963163]

\section{ACCURACY OF CHARACTERISTIC X-RAY LINES}

The measurement of poloidal and toroidal plasma rotation is limited by precision in the determination of spectral line position. For well-known line shapes, one could achieve the values of 1/50-1/80 of FWHM. Typically, resonance lines of $\mathrm{He}-$ and H-like ions are measured. The temperature range is limited at the lower end by sufficient population of the He-like ground state and the excitation rates, at the upper end by the disappearance of the H-like ions due to ionization. For Ar, $\Delta \lambda / \lambda_{\text {FWHM }}$ ranges from $300 \mathrm{ppm}$ to $1100 \mathrm{ppm}$, for Fe and $\mathrm{Kr}$ from 600 to $1400 \mathrm{ppm}$, and for Ne-like $\mathrm{W}$, the range is somewhat smaller, from 600 to $1000 \mathrm{ppm}$. The inaccuracy of the spectral lines should therefore be lower than $5 \mathrm{ppm}$, at least not larger than $10 \mathrm{ppm}$. Examining the NIST X-ray transition energies database, ${ }^{1}$ error levels are low enough only for $\mathrm{K} \alpha$ transitions to meet the required accuracy. The $\mathrm{x}$-ray lines consist of many components, due to additional holes in the outer shells; therefore the lines are asymmetric and appear broader. The width of $\mathrm{x}$-ray lines is shown in Fig. 1. The $\mathrm{K} \alpha$ lines are narrower than $500 \mathrm{ppm}$ between approximately $3 \mathrm{keV}(\mathrm{z}=18, \mathrm{Ar})$ and $30 \mathrm{keV}(\mathrm{z}=54, \mathrm{Xe})$. There is a broad minimum around $10 \mathrm{keV}(\mathrm{Ge})$. $\mathrm{L} \alpha$ is $2-2.5$ times broader than $\mathrm{K} \alpha$ at the same energy. Even though $\mathrm{K} \alpha$ lines are narrow enough to define the positions for $\mathrm{Ar}, \mathrm{Fe}, \mathrm{Kr}$, and $\mathrm{W}$ lines, the width is still too large to measure the resolution of the

\footnotetext{
Note: Contributed paper, published as part of the Proceedings of the 21st Topical Conference on High-Temperature Plasma Diagnostics, Madison, Wisconsin, USA, June 2016.

a) Author to whom correspondence should be addressed. Electronic mail: gbertschinger@web.de
}

spectrometers. Therefore the resolution must be guaranteed by design. However, for the measurements of plasma rotation, i.e., shift of the spectral lines, the accuracy is better than 3-5 ppm and compares favorably with the possible resolution for the Doppler broadened lines. Suitable calibration lines are shown in Fig. 1 and Table I, for He-like $\mathrm{Kr}$, there is no calibration line and the alignment must be done independently.

\section{ALIGNMENT OF IMAGING BRAGG SPECTROMETERS}

The Imaging Bragg spectrometers used for diagnostics on magnetic fusion devices are typically modified Johann spectrometers with symmetric reflection. Alignment can be done in air with visible light as the spherical Bragg crystals behave as monochromatic mirrors. But for commercially available crystals, there is a miscut, i.e., the crystal layers are not absolutely parallel to the surface and the reflection of the $\mathrm{x}$-rays is somewhat different to the reflection of visible light on the surface. The miscut is measured according to the lines given by Covita. ${ }^{4}$ For this measurement, the crystal is placed on a rotary device, the center of the spherical crystal as well as the Rowland sphere must coincide with the axis. The center of the crystal sphere is found by autocollimation, the center coincides with the axis if the focal point does not change, when the axis is rotated. With this arrangement, a Johann spectrometer using an $\mathrm{x}$-ray tube with a suitable characteristic $\mathrm{K} \alpha$ line is set up. When the crystal is rotated, the focus on the x-ray detector should not change, if a miscut is present, the focus moves sinusoidally. The crystal must be symmetric to the rotation axis to keep the imaging errors 


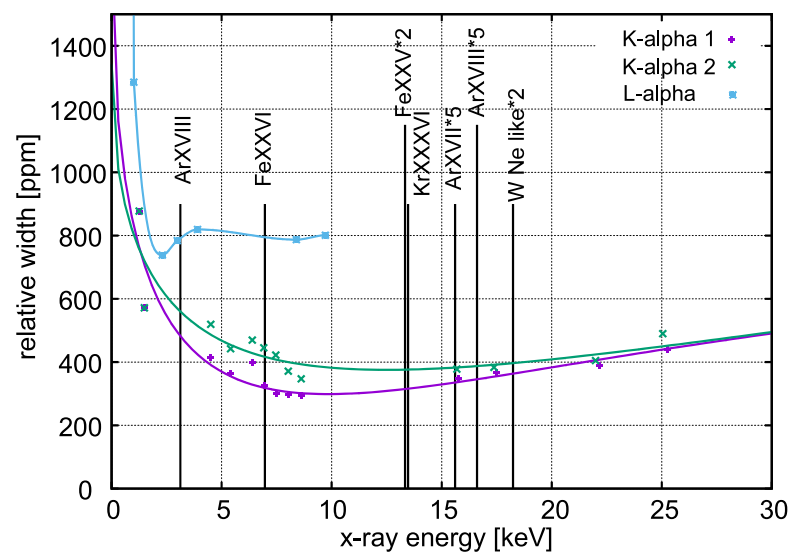

FIG. 1. Width of $\mathrm{K} \alpha_{1}, \mathrm{~K} \alpha_{2}$, and $\mathrm{L} \alpha$ lines. $^{2}$ Curves are just to guide the eyes. The energies for $\mathrm{K}, \mathrm{Co}$, and $\mathrm{Rb}$ are indicated for the calibration of Lya of $\mathrm{H}$-like $\mathrm{Ar}-$, $\mathrm{Fe}-$, and $\mathrm{Kr}$-ions, respectively. He-like $\mathrm{Ar}$ and $\mathrm{Fe}$, as well as $\mathrm{Ne}$-like $\mathrm{W}$ coincide in higher order with $\mathrm{Rb}, \mathrm{Zr}$, and $\mathrm{Tc}$ as well as $\mathrm{H}$-like Ar with $\mathrm{Nb}$.

and hence the line shape constant. The measurement can be done in air, if a sufficiently high $\mathrm{x}$-ray energy is chosen, for smaller spectrometers $>10 \mathrm{keV}$ and for larger $>15 \mathrm{keV}$. After having determined the miscut, the alignment of the crystal and the detector in the spectrometer box can be done using the properties of imaging Bragg spectrometers with spherical crystals. The positions should be measured by a Coordinate Measurement Machine (CMM), and the modern CMM covers volumes of a few $\mathrm{m}^{3}$ with an accuracy of some $\mu \mathrm{m}$ (Fig. 2).

\section{IN SITU CALIBRATION WITH X-RAY FLUORESCENCE}

In situ wavelength calibration of $\mathrm{x}$-ray spectrometers is highly desirable not only to check for mechanical stability and detector integrity, but also for walk of the spectra due to radiation heating of the crystal during the pulse..$^{5} \mathrm{~A}$ thermonuclear plasma is an intense source of low energy $\mathrm{x}$-rays. Radiation

TABLE I. K $\alpha$ lines suitable for calibration of the commonly used $\mathrm{x}$-ray lines. Lines have been chosen to fit into an interval of $1 \%$ : The diffraction order must be allowed for the crystal, check by $\mathrm{XOH}^{3}{ }^{3}$ Most suitable lines are shown in bold.

\begin{tabular}{|c|c|c|c|c|c|}
\hline Spectral line & $\begin{array}{l}\text { Energy } \\
(\mathrm{eV})\end{array}$ & $\begin{array}{c}\text { X-ray charge } \\
\text { line }\end{array}$ & $\begin{array}{c}\text { Energy } \\
(\mathrm{eV})\end{array}$ & $\begin{array}{l}\text { Dev. } \\
(\%)\end{array}$ & $\begin{array}{l}\text { Diffr. } \\
\text { order }\end{array}$ \\
\hline \multirow[t]{2}{*}{ Ar XVII K $\alpha$} & \multirow[t]{2}{*}{3121.87} & $36 \mathrm{~K}_{2}$ & 12595.424 & 0.864 & 4 \\
\hline & & $40 K \alpha_{2}$ & 15690.645 & 0.521 & 5 \\
\hline \multirow[t]{6}{*}{ Ar XVIII Ly $\alpha$} & \multirow[t]{6}{*}{3320.58} & $19 K \alpha_{1}$ & 3313.948 & -0.200 & 1 \\
\hline & & $19 K \alpha_{2}$ & 3311.196 & -0.283 & 1 \\
\hline & & $32 \mathrm{~K} \alpha_{1}$ & 9886.52 & 0.755 & 3 \\
\hline & & $37 \mathrm{~K} \alpha_{2}$ & 13335.88 & 0.403 & 4 \\
\hline & & $41 K \alpha_{1}$ & 16615.16 & 0.074 & 5 \\
\hline & & $41 K \alpha_{1}$ & 16521.28 & -0.492 & 5 \\
\hline \multirow[t]{3}{*}{$\mathrm{Fe} X X V \mathrm{~K} \alpha$} & \multirow[t]{3}{*}{6668.51} & $37 \mathrm{~K} \alpha_{1}$ & 13395.49 & 0.438 & 2 \\
\hline & & $37 \mathrm{~K} \alpha_{2}$ & 13335.88 & -0.009 & 2 \\
\hline & & $45 \mathrm{~K} \alpha_{2}$ & 20073.67 & 0.341 & 3 \\
\hline Fe XXVI Ly $\alpha$ & 6962.60 & $27 \mathrm{~K} \alpha_{1}$ & 6930.378 & -0.463 & 1 \\
\hline Kr XXXVI Ly $\alpha$ & 13469.1 & $37 \mathrm{~K} \alpha_{1}$ & 13395.49 & -0.547 & 1 \\
\hline W Ne-like & 9119.2 & $43 K \alpha_{2}$ & 18250.9 & 0.069 & 2 \\
\hline
\end{tabular}

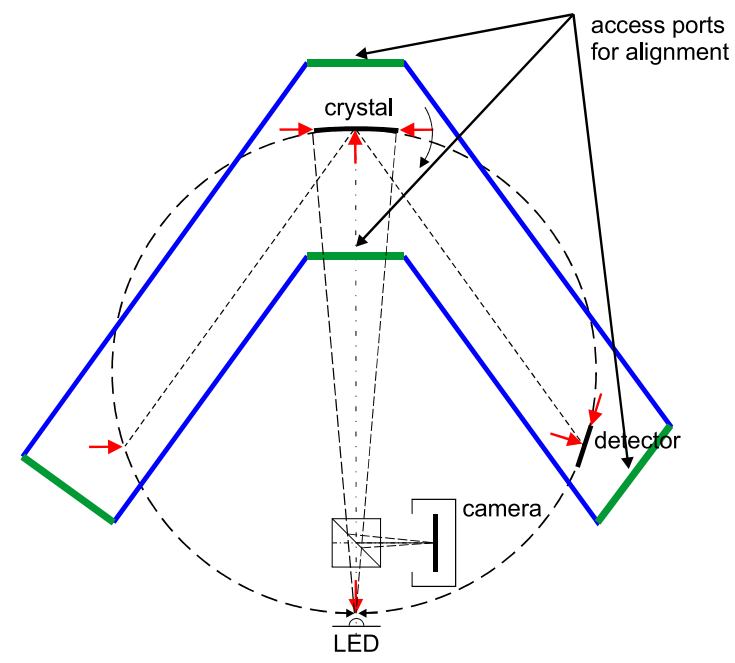

FIG. 2. Sketch for the alignment of an imaging Bragg spectrometer using a CMM. The center of the crystal spheres, the crystals and the detector must be accessible by the probes of the CMM, and there must be a direct view for auto collimation. Accuracies of $5 \mu \mathrm{m}$ and hence angular accuracy of $<10 \mu \mathrm{rad}$ are possible. The alignment should be checked by suitable $\mathrm{x}$-rays and the dimensions of the source should be chosen to illuminate the same part of the crystal as in the measurement.

losses are typical a few hundred $\mathrm{kW}$, for ITER several MW are to be expected. Even in the narrow, $4 \mathrm{~cm}$ wide viewing channel of the $\mathrm{x}$-ray spectrometers on ITER, $1 \mathrm{~m}$ behind the blanket, a surface is illuminated with about $2.5 \mathrm{~mW} / \mathrm{cm}^{2}$ for a radiation in the center of $1 \mathrm{MW}$. For this study, a thermal plasma concentrated at the center of ITER is assumed and only Bremsstrahlung and recombination radiation from lowand intermediate-z impurities are considered. At high energies, both Bremsstrahlung and recombination radiations decay exponentially. The absorption of $\mathrm{x}$-ray energy $<100 \mathrm{keV}$ is mainly via photoelectric absorption, the cross section is largest just above the threshold and decreases rapidly for higher energies, at the threshold, the absorption cross section increases

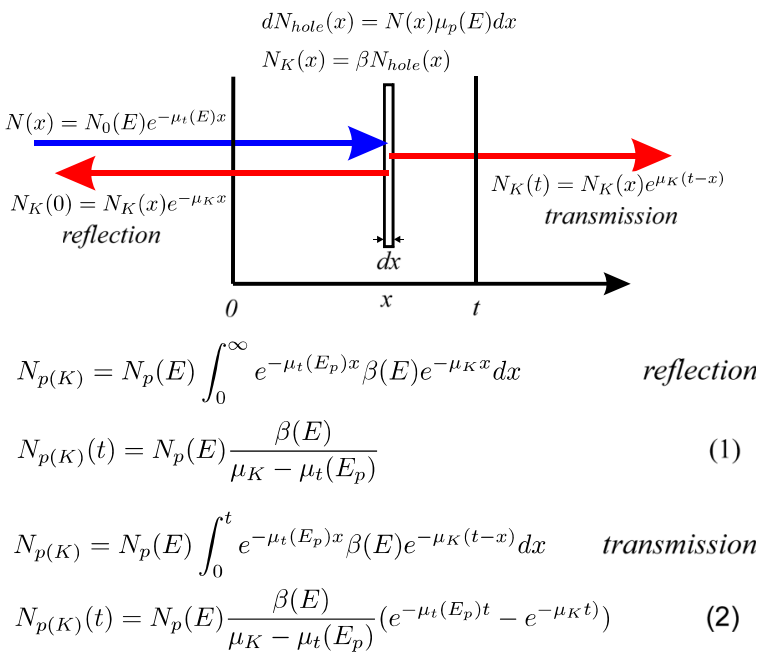

FIG. 3. 1-D fluorescence of pure material: X-rays entering the substrate are absorbed at $\mathrm{x}$ and produce holes in the electron shell. A fraction $\beta$ emits a $\mathrm{K} \alpha$ photon which can leave the substrate. Both the incoming and the K $\alpha$ photons are attenuated by total absorption coefficients $\mu_{\mathrm{t}}$ and $\mu_{\mathrm{K}}$, respectively. For low energies $<100 \mathrm{keV}$, photoelectric absorption is the dominant absorption process such that $\mu=\mu_{\mathrm{t}} . \beta$ is the product of the jump ratio, the fluorescence yield, and the line fraction. 

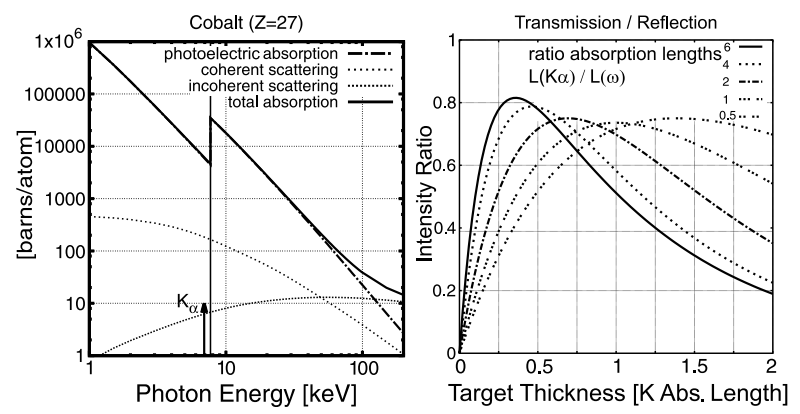

FIG. 4. (a) Left: energy dependence of absorption cross sections. ${ }^{6}$ (b) Right: the intensity of a fluorescence target in transmission is $70 \%-80 \%$ of a reflection target. It depends on the absorption coefficient of the incoming radiation. Target thickness is in units of the absorption length and is valid for all elements. Whereas the intensity of a reflection target increases with thickness and saturates for thick targets, a transmission target rises to $70 \%-80 \%$ and decreases with thickness. The optimum target thickness is rather small, $0.4-0.5 \times$ absorption length.

with energy by factor 8-9 (Fig. 4(a)). X-ray absorption is therefore very efficient in producing holes in the electron shells, more than $80 \%$ of the photons with energies above the $\mathrm{K}$ edge produce a hole in the K-shell. The holes are filled up again by electrons of the outer shell, emitting a photon or an Auger electron. Fluorescence can be observed in reflection or in transmission, but transmission targets are easier to integrate into a line of sight. A model for $\mathrm{x}$-ray fluorescence is shown in Fig. 3.

To compare fluorescence targets in transmission with reflection targets, we relate the $\mathrm{K} \alpha$ flux of a transmission target to the flux of a thick reflection target as a function of target thickness. Fig. 4(b) shows the absorption cross sections and the efficiency of a fluorescence target, parameter is the ratio between the absorption coefficients of the incoming $\mathrm{x}$-ray to the $\mathrm{x}$-ray at $\mathrm{K} \alpha$. The ratio is about 6 at the $\mathrm{K}$-edge and decays rapidly with energy.

The radiation of a thermal plasma decays $\sim \exp (-E / T)$ at high energy, where $\mathrm{E}$ is the photon energy and $\mathrm{T}$ is the electron temperature, both in $\mathrm{keV}$. Independent of the energy, one incoming photon can produce one hole in the K-shell only and the relevant figure is the photon flux, $\sim 1 / \operatorname{Eexp}(-E / T)$. Using Eq. (2), photon cross sections ${ }^{6}$ and $\mathrm{x}$-ray fluorescence cross sections, ${ }^{7}$ the contribution is integrated over the photon flux above threshold. Fig. 5 shows the Ka fluence of Co as a function of target thickness and plasma temperature.
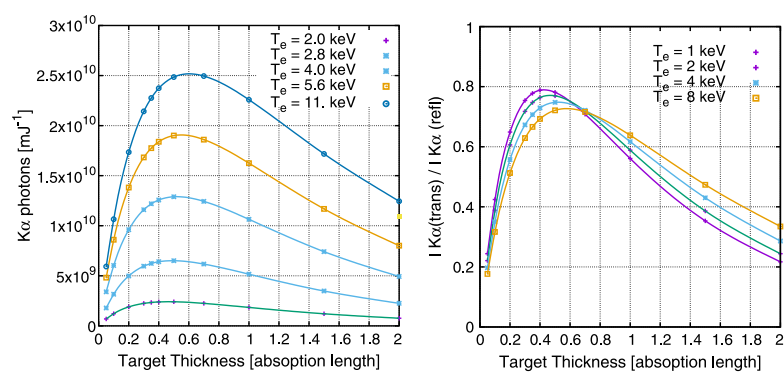

FIG. 5. K $\alpha$ fluence for a Co target for thermal plasma radiation versus target thickness, normalized to $1 \mathrm{~mJ} / \mathrm{cm}^{2}$ total radiation (left) and (right) relative to a reflection target. Optimum target thickness is about $0.5 \times$ absorption length.
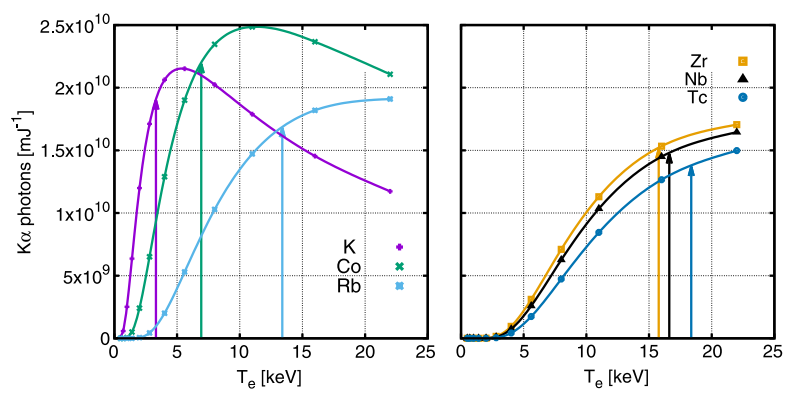

FIG. 6. X-ray fluorescence versus temperature for $\mathrm{K}, \mathrm{Co}, \mathrm{Rb}$ (left) and $\mathrm{Zr}$, $\mathrm{Nb}, \mathrm{Tc}$ (right). Thickness is $0.5 \times$ absorption length.

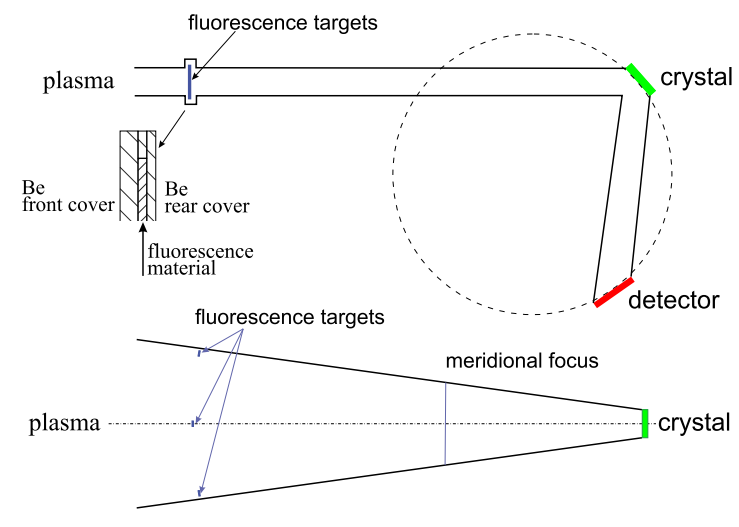

FIG. 7. Fluorescence targets on ITER (schematic).

TABLE II. Count rate estimates on ITER for fluorescence targets, size $4 \mathrm{~cm}^{2}$ in the viewing channel, $1 \mathrm{~m}$ behind the blanket. Plasma radiation is $1 \mathrm{MW}$. Strong lines are in bold italics.

\begin{tabular}{|c|c|c|c|c|c|c|}
\hline Line & $\begin{array}{c}\text { Energy } \\
(\mathrm{keV})\end{array}$ & $\begin{array}{c}\text { Crystal } \\
\text { meas. }\end{array}$ & $\mathrm{x}$-ray line & $\begin{array}{l}\text { Crystal } \\
\text { calibr. }\end{array}$ & Counts/s & $\begin{array}{c}\mathrm{Te} \\
(\mathrm{keV})\end{array}$ \\
\hline $\operatorname{Ar}$ XVII K $\alpha$ & 3.12187 & $\mathrm{Qu}(110)$ & $\operatorname{Zr}(40) \mathrm{K} \alpha_{2}$ & $\mathrm{Qu}(550)$ & 6 & 25 \\
\hline Ar XVIII Ly $\alpha$ & 3.32058 & $\mathrm{Qu}(110)$ & $\mathrm{Nb}(41) \mathrm{K} \alpha_{1}$ & $\mathrm{Qu}(550)$ & 5.5 & 25 \\
\hline Ar XVIII Ly $\alpha$ & 3.32058 & $\mathrm{Qu}(110)$ & $K(19) K \alpha_{1}$ & $\mathbf{Q u}(110)$ & 540 & 5 \\
\hline Ar XVIII Ly $\alpha$ & 3.32058 & $\mathrm{Qu}(102)$ & $K(19) K \alpha_{1}$ & $\mathbf{Q u}(102)$ & 470 & 5 \\
\hline $\mathrm{Fe} X X V \mathrm{~K} \alpha$ & 6.66851 & $\mathrm{Qu}(220)$ & $\mathrm{Nb}(41) \mathrm{K} \alpha_{1}$ & $\mathrm{Qu}(550)$ & 5.5 & 25 \\
\hline $\mathrm{Fe} X X V \mathrm{~K} \alpha$ & 6.66851 & $\mathrm{Ge}(224)$ & $\mathrm{Rb}(37) \mathrm{K} \alpha_{1}$ & $\mathrm{Ge}(448)$ & 25 & 20 \\
\hline Fe XXVI Ly $\alpha$ & 6.9626 & $\mathrm{Si}(224)$ & $\operatorname{Co}(27) K \alpha_{1}$ & $\mathrm{Si}(224)$ & 135 & 10 \\
\hline KrXXXVI Ly $\alpha$ & 13.4691 & $\operatorname{Si}(664)$ & $\operatorname{Rb}(37) \mathrm{K} \alpha_{1}$ & $\operatorname{Si}(664)$ & 20 & 20 \\
\hline W Ne-like & 9.1192 & $\operatorname{Si}(620)$ & $\mathrm{Tc}(43) \mathrm{K} \alpha_{2}$ & $\operatorname{Si}(12,40)$ & 4.5 & 20 \\
\hline
\end{tabular}


With the optimum target thickness of $0.5 \times$ absorption length, the $\mathrm{K} \alpha$ fluence for different targets can be calculated to get a count estimate. Fig. 6 shows the $\mathrm{K} \alpha$ fluence for the different calibration elements proposed above. There is a broad maximum for a temperature about $1.7 \times \mathrm{K} \alpha$ energy, for all elements, maximum fluence is between 1.5 and $2.5 \times 10^{10} \mathrm{~K} \alpha(1 / \mathrm{mJ})$. If the $\mathrm{K} \alpha$ line appears in the same order as the measurement line, the intensity is reasonable. In higher orders, the intensity is too low due to low reflectivity of the crystals (Table II). But at any rate, each of the spectrometer channels on ITER has at least one calibration line. The other lines can then be cross calibrated. Fig. 7 shows a sketch for the fluorescence target on ITER. The fluorescence substrate is enclosed in Be to protect it against oxidation. In 1st order, the fluorescence screen is still transparent. X-ray fluorescence of L lines of cadmium has been proposed ${ }^{8}$ for the calibration of the He-like argon spectra, and tried on EAST ${ }^{9}$ and KSTAR, but no success has been reported yet, $\mathrm{L}$ lines are inferior to $\mathrm{K} \alpha$ with respect to accuracy, width, and intensity. To summarize, $\mathrm{x}$-ray spectrometers can be reliably set and calibrated using $\mathrm{K} \alpha$ lines, in some cases, fluorescence targets for in situ calibration are available.

${ }^{1}$ See http://www.nist.gov/pml/data/xraytrans/ for NIST X-ray Transition Energies Database.

${ }^{2}$ D. Roberts and M. Sulkanen, AXAF Project Science, http://wwwastro. msfc.nasa.gov/xraycal/linewidths.html.

${ }^{3}$ S. Stepanov, XOH, http://x-server.gmca.aps.anl.gov/x0h.html.

${ }^{4}$ D. S. Covita et al., Rev. Sci. Instrum. 79, 033102 (2008).

${ }_{5}^{5}$ L. Delgado-Aparicio et al., Plasma Phys. Controlled Fusion 55, 125011 (2013).

${ }^{6}$ M. J. Berger et al., XCOM, http://www.nist.gov/pml/data/xcom/.

${ }^{7}$ M. Sanches del rio et al., XRAYLIB tables, http://ftp.esrf.eu/pub/scisoft/ xraylib/xraylib_tables_v2.3.pdf.

${ }^{8}$ L. F. Delgado-Aparicio et al., "Calibration activities for high-resolution X-ray crystal imaging spectrometers," in Proceedings of the 22nd ITPA Topical Group Meeting on Diagnostics, Moscow, Russia, 14-17 May 2012.

${ }^{9}$ B. Lyu et al., Rev. Sci. Instrum. 85, $11 \mathrm{E} 406$ (2014). 